\title{
A Vivência da Implantação do Programa de Qualidade Total:Um Estudo de Caso
}

Simone Oliveira, M. Sc.

Pesquisadora do Centro de Estudos da Saúde do Trabalhador e Ecologia Humana CESTEH/ENSP/FIOCRUZ

Rua Leopoldo Bulhões, 1480 - Manguinhos - cep 21.041-210

Rio de Janeiro - RJ - Fax: 021- 2703219 têxtil

Palavras chave: Programa de Qualidade Total, inovação tecnológica, indústria

Key words: Total Qualit Control, technological inovation, textil industry

\section{RESUMO}

A pesquisa, que baseou-se em estudo de caso de uma indústria têxtil, no município de Nova Friburgo(RJ), procurou perceber como os Programas de Qualidade Total são pensados para aumentar a qualidade do produto, sem contudo modificar a qualidade de vida dos trabalhadores. Identificou a convivência de situações diversas de precárias condições de trabalho ou de seu processo com outras de sofisticadas exigências - abstração, controle da qualidade à nivel do operador, generalização do conceito formecedor/cliente etc. -; que esbarra em uma força de trabalho de baixa escolaridade, desenvolvendo um ambiente tenso, intensificando o ritmo de trabalho, sem contudo promover ganhos concretos para os trabalhadores.

\section{ABSTRACT}

The case study of a textile industry, in country of Nova Friburgo (Rio de Janeiro), had the purpose to understand how the implementation of Total Quality Programas are formulated in order to increase the product quality without modifying, though, the worker's life quality. It was detected the occurrence of precarious work condition situations, or of their process involving other sophisticated requirements - abstraction, control interiorization, generalization of the concept vendor/client, etc..- which are confronted with a low level scholarship labour force creating a tense atmosphere, where with a labour rhythm intensification, whithout producing actual gains for workers, though. 


\section{PRODUÇÃO}

\section{Introdução}

As recentes formas de organização do trabalho, no Brasil, baseadas no "modelo japonês" de gestão, se traduzem pela implantação de Programas de Qualidade Total (PQT). Estes programas trazem na sua concepção mudanças na qualificação dos trabalhadores e exigem uma crescente intervenção destes nos processos produtivos. Exigem maior participação e maior envolvimento racional e emocional. Os trabalhadores devem passar a entender e a influir no processo de produção, adquirindo maior qualificação, assumindo a polivalência e passando por uma maior carga de treinamentos. $\mathrm{O}$ trabalhador, em todos os momentos da vida, deve passar a viver e a pensar, essencialmente, na empresa.

O novo paradigma produtivo, que hoje se configura como alternativo ao fordismo, se desenvolveu em meio ao incremento das inovações tecnológicas $e$ organizacionais e à descentralização e abertura do mercado internacional. Segundo Harvey (1994), ele se apóia na flexibilidade dos processos e mercados de trabalho, dos produtos e padrões de consumo. Nele, a tecnologia microeletrônica e as novas formas de organização do trabalho têm capacidade de integrar o que a base técnica eletromecânica e a organização fordista do processo de trabalho dividiram, tendendo à criação de um ambiente de trabalho mais participativo, com maior dependência das empresas com relação a seus trabalhadores. No entanto, conforme afirma Leite (1993:195), embora esse novo modelo traga em si um potencial integrador e indique transformações, no processo de trabalho, direcionadas a facilitar a participação dos trabalhadores, esta potencialidade pode-se concretizar de maneira muito diferente e causar "impactos sobre o trabalho que apontam mais no sentido da sua precarização do que de seu enriquecimento".

\section{A Importação da Qualidade e sua Aplicabilidade}

A idéia de incorporar-se à modernidade e ao mercado internaciona!, através da maior eficiência, melhor qualidade e mais competitividade, é hoje um consenso do empresariado brasileiro.

No entanto, a "importação da qualidade" traz algumas questões quanto à adequação do modelo japonês a outros países. Muitos presumem ser apenas um conjunto de técnicas que, pela vontade do empresariado, pode ser implantado com certa garantia de sucesso. Crêem que o modelo japonês possui aplicabilidade universal, ou seja, o "trabalhador está pronto para agir do jeito japonês se o empresariado o tratar corretamente" (Humphrey, 1989:331).

Mas, ao se considerar as diferenças sócio-econômicas e culturais internacionais, há necessidade de se verificar, no âmbito de cada país, como o novo paradigma de gestão da produção 
vem sendo traduzido e adaptado. Ou, de outra maneira, que não existem 'modelos' universais que sejam transponiveis para outro país (Ferreira et al., 1991). Não se deve perder de vista a diversidade do real, os diferentes modos de absorção das experiências nacionais a estes principios, pois estes se revestem de caracteristicas próprias ao se desenvolverem em realidades distintas.

Distante das condições que propiciaram o nascimento do modelo japonês, o Brasil baseia-se em relações de trabalho com práticas de gerenciamento de tradição autoritária e muito hierarquizadas entre gerências e operários, onde a diferença de educação e formação só fazem acentuá-las. No Brasil, os recursos humanos são abundantes, baratos e substituíveis, enquanto no Japão é um dos recursos mais valorizados. Além disso, o Brasil possui uma concentração de renda das maiores do mundo $(10 \%$ detêm $50 \%$ da renda nacional), com uma renda per capita de 1.500 dólares anuais, que refletem as desfavoráveis condições de vida da população trabalhadora. Apesar de ser "um dos dez paises com maior Produto Interno Bruto do mundo, os níveis salariais dos trabalhadores são dos menores do mundo, mas as taxas de lucros e salários de dirigentes de empresas são das maiores do mundo" (Tauille, 1993:100).

Outro agravante é que no Brasil nunca existiu consumo de massa. O trabalhador nunca teve acesso à compra do que produz, dificultando o controle da qualidade onde o trabalhador tem que se colocar no lugar do consumidor. Cabe destacar ainda que, no caso brasileiro, há um amplo contigente de desempregados e sub-empregados, amplo setor informal e nível de qualificação formal bastante baixo.

Em suma, como destaca Coriat (1994:12), enquanto sistema coerente de gestão de produção, o motivo fundamental de sua não absorção tem a ver com o fato de que "empresários brasileiros criaram sua atividade (algumas vezes sua prosperidade) sobre o trabalho não ou fracamente qualificado e sub-remunerado, num recurso sistemático de utilização de uma mão-de-obra instável e precária". Diante desta realidade, continua Coriat, introduzir um modelo baseado na qualificação do trabalho, na estabilidade de emprego e nos mercados internos do trabalho vai contra todas as experiências realizadas pelo empresariado brasileiro. $\mathrm{E}$, dessa forma, fica compreensível que eles utilizem os métodos japoneses como um conjunto de receitas.

\section{Um Estudo de Caso da Indústria Têxtil}

As transformações ocorridas, na indústria têxtil, nas últimas décadas, com a incorporação de um novo maquinário, mais produtivo e mais caro, de base microeletrônica, levaram à modificação do perfil dos trabalhadores e causaram mudanças em termos da composição da mão-de-obra e da qualificação 


\section{PRODUÇÃO}

profissional. Somou-se a isso o desenvolvimento da indústria quimica, responsável pela produção das fibras sintéticas, que proporcionou à indústria têxtil solucionar problemas relacionados às fibras naturais, que devido à sua fragilidade ocasionavam paradas freqüentes e desequilíbrio de eficiência. A introdução das fibras sintéticas possibilitou o aumento da velocidade da produção e viabilizou o desenvolvimento de novos produtos e consequentemente diversificação das linhas de produção (Weiss et al., 1993).

Este artigo trata de um estudo de caso, onde se avaliou a implantação do Programa de Qualidade Total (PQT), numa fábrica específica, destacando as mudanças ocorridas nas relações de trabalho. A pesquisa foi realizada numa indústria têxtil, no Municipio de Nova Friburgo (RJ), que produz aviamentos têxteis: elásticos para lingerie, etiquetas bordadas, fitas decorativas e fitas rigidas. Entre a administração e a produção, possui no seu total 361 funcionários. $\mathrm{Na}$ produção se encontram 212 trabalhadores - sendo 132 homens e 80 mulheres, e na administração 149 - sendo 92 homens e 57 mulheres. Nos últimos anos a empresa vem incorporando equipamentos de microeletrônica, que por sua vez, geram modificações nas linhas de produção de alguns artigos, chegando ao enxugamento das seções e à eliminação de outras. Atualmente fazem parte de seu processo de produção teares eletrônicos, com design de seus produtos realizados pelo sistema CAD (Computer Aided Design).
Para se manter competitiva no mercado, a partir de 1991, esta fábrica iniciou a implantação do $\mathrm{PQT}$. A pesquisa utilizou questionários para criar uma amostra estratificada do universo de pessoas pesquisadas, entrevistas com o objetivo de aprofundar questões apontadas pelos questionários, observação direta no local de trabalho para captar o universo das mudanças e as percepções e vivências dos trabalhadores em seu contexto de trabalho.

\section{Noções e Princípios da Qualidade e os Conflitos com a Realidade}

O processo de implantação do PQT se deu de forma turbulenta, com grande impacto nessa empresa tradicional, de cultura paternalista, onde as relações hierárquicas eram pautadas nos favores $\mathrm{e}$ nos favoritismos entre chefia e empregado, longe do rigor da qualidade e muito mais próximas das relações tipo familiares.

Estabelecer um cronograma das atividades de implantação foi um dos primeiros passos para a efetivação do programa, que teve como principal dispositivo palestras de conscientização. O objetivo básico dessas palestras era explicar os conceitos de qualidade e quais os resultados que a empresa pretendia atingir. Era colocado a necessidade do trabalhador conhecer todo o processo fabril, de como deveria se localizar dentro dele, tomando consciência da 


\section{PRODUÇÃO}

responsabilidade da atividade que desenvolvia para toda a organização, através da técnica do trabalho de clientes internos, onde um setor é sempre o cliente de outro setor, onde um trabalhador é sempre o cliente próximo de um outro trabalhador, tendo que se ter um bom atendimento em cada etapa da produção. Os trabalhadores que freqüentavam essas palestras, quase que diariamente, eram selecionados por área. $O$ intuito foi de realizar uma profunda imersão do corpo de funcionários na questão. Em suas dinâmicas, os seminários também utilizaram vídeos sobre a Qualidade Total, que divulgavam a essência de seus principios: qualidade intrínseca, preço acessivel e qualidade no atendimento, todos com um único objetivo: a satisfação total do cliente.

Para obtenção dessa satisfação, fica reforçada a idéia da necessidade de se desenvolver um espírito de cooperação $e$ parceria dos trabal hadores com a empresa, onde se parte do princípio que a dependência de um e de outro são prérequisitos para o crescimento de ambos. Dessa forma o conteúdo dessas palestras tem um cunho muito mais ideológico do que técnico. Um sistema de idéias, valores e filosofias que muitas vezes fica distante do dia a dia do trabalhador, exigindo abstrações de pouco significado imediato para ele.

Algumas das iniciativas do $\mathrm{PQT}$ não puderam sequer serem implantadas, como por exemplo, o Programa de Sugestões. Nele, o autor de uma possível sugestão incorporada receberia uma premiação de $10 \%$ do resultado que sua idéia pudesse gerar. No entanto, esse programa apresentou um fracasso imediato. Os trabalhadores não sabiam escrever suas idéias, evidenciando o baixo grau de escolaridade, onde $70 \%$ têm o primário incompleto. Mesmo sofrendo alterações, deixando de lado a sugestão escrita para aquela falada em comitês, o programa continuou não apresentando resultados, pois havia ainda o medo de se dizer o que se pensa. Eram anos de uma gerência autoritária: "Você tem reunião, precisa que o pessoal fale. Fica todo mundo quieto, ficam com medo de falar. Como é que vai resolver os problemas? Falta de palavras para falar, não tinham como se expressar". Neste depoimento, uma exoperária, integrante da equipe de qualidade e produtividade explicita as duas questões: a dificuldade e o medo de se expressar. Baixa escolaridade e submissão. Ou como prefere acreditar o gerente industrial, que o problema seja uma questão de personalidade: "Não tivemos sucesso no plano de sugestões, $o$ pessoal é muito inibido".

Esta iniciativa dentro da implantação do programa de qualidade foi a que mais evidenciou a pouca qualificação formal dos trabalhadores da empresa, mostrando o inevitável conflito entre as novas necessidades técnicas e a realidade da mão-de-obra. A reflexão sobre este ponto levou a identificação da baixa escolaridade como maior obstáculo para o avanço do programa. A partir desta identificação, foi sugerida pelo coordenador do programa, 


\section{PRODUÇÃO}

a elaboração de meios para superar esse problema. Um deles foi a criação do supletivo e a exigência da $5^{\mathrm{a}}$ Série como norma para contratação.

Para a aplicação do PQT, foi estabelecido o Programa de Limpeza, considerado como um pré-requisito e conhecido como a implantação dos cinco $\boldsymbol{S}$, a saber: Seiso, Seiketsu, Seiki, Seiton e Shitsuke; que significam limpeza do local de trabalho e dos empregados; utilização racional de recursos para evitar desperdício, descarte de itens desnecessários, liberação do espaço; organização de forma disciplinada e racional dos itens e instrumentos de trabalho; disciplina e obediência às normas, aos padrões definidos, auto disciplina.

Outra iniciativa foi a criação dos Grupos de Produtividade e Qualidade (GPQ) - Times Works - grupos de trabalho formados por equipes heterogêneas, para discutir um problema determinado, composto por seis ou sete pessoas que estavam diretamente ligadas ao problema, variando de acordo com a dimensão deste, que se reuniam uma vez por semana. Caso o problema fosse eliminado, aquela antiga perda, se transformava em ganho. dessa forma, as equipes recebiam $10 \%$ do resultado que o trabalho gerava. Também encontraram dificuldades na sua continuidade, apesar de apresentarem, segundo os trabalhadores, bons resultados. Paulatinamente, em função dos obstáculos e resistências, os grupos foram perdendo a sua força e motivação. As chefias das seções relutavam em aceitar propostas que interferissem no modo de organizar e produzir da sua seção.

\section{Mudança de Concepção: Cultura e Relações de Poder}

Essa não aceitação por parte das gerências e chefias é considerada um lugar comum nas experiências de implantação de programas de qualidade. A não aceitação se transforma em resistência, principalmente, quando se trata de aumentar a autonomia dos trabalhadores que coloca em xeque o modo como a autoridade é normalmente entendida e exercida. Tal situação pôde ser constatada também neste caso: "dão a responsabilidade mais não dão a autoridade para ele fazer aquilo". Essa descrição do problema da autonomia feita pelo gerente de qualidade e produtividade destaca a questão de um operário submetido à uma organização taylorizada e submisso a uma chefia autoritária, que não dá o devido valor ao conhecimento adquirido através do exercício da atividade.

A qualidade total implica em alteração do método de organização do processo de trabalho, com relacionamento menos verticalizado, mais cooperativo, entre as chefias e operadores, mais voltado para o trabalho em equipe e centrado na noção de autonomia responsável. A construção desse novo perfil de trabalhador participativo pressupõe, simultaneamente, uma mudança no perfil das chefias e, 
portanto, no relacionamento entre chefia e trabalhadores. Esse novo perfil de chefia, uma nova exigência de comportamento, a de passar a ouvir muito mais problemas pessoais dos funcionários, é resultado da necessidade de que os novos chefes, dentro de um programa de qualidade, sejam também os condutores das informações. Eles levam mensagens da alta gerência e levam mensagens dos trabalhadores. Levam e trazem; eles são os mentores do novo processo e também seus canais de comunicação, aqueles que devem implementar a cooperação geral da fábrica e, portanto, sob vários aspectos, pessoais e profissionais, devem ser flexíveis. Modifica por sua vez, a trajetória profissional das chefias no âmbito da produção, que anteriormente era exercida pelos operários com longos anos de experiência e de grande conhecimento do processo de trabalho, e que agora passam a ser requisitados externamente, com a exigência de um maior nível de escolaridade.

Aumentar a qualificação e afinar o corpo dos funcionários com uma idéia comum de qualidade, acaba por desenvolver a necessidade de um outra ferramenta da qualidade: o trabalho em equipe. Através da criação de grupos de trabalho, reuniões freqüentes, há um consenso entre as chefias e os gerentes da empresa que estabeleceu-se um maior entendimento entre as seções. $O$ trabalho em equipe busca a não omissão de erros e falhas e, também, a não responsabilização individual destes e, sim, que sejam mapeados e solucionados coletivamente.
Daí, o fortalecimento do ideal de identificação do trabalhador com a empresa.

\section{O Programa e as Seções}

Ainda com relação à implantação do PQT na empresa estudada, foram ministrados vários cursos internos $\mathrm{e}$ externos, elevando a carga de treinamento, com o incremento da hora/homem anual.

O processo de produção da empresa está dividido em cinco grandes seções, que são descritas a seguir em ordem de fabricação: Preparação de Fio de Urdimento Rígido (PF1); Preparação de Fio Elástico (PF2); Tecelagem; Tinturaria e Empeçamento

Foram introduzidas modificações na área de preparação de fios, PF1 e PF2, com a inscrição de todos os funcionários no programa de treinamento, que passaram a aprender o trabalho da enfiação dos teares na tecelagem. Quando há necessidade de contratação, estes são requisitados internamente. Na tecelagem, o trabalho de enfiação foi o que sofreu maiores modificações no seu processo, definidas a partir de estudos de tempos e métodos. Houve a realização de treinamentos para emendas, pois observava-se diferenças de desempenho entre os enfiadores, com reflexos na eficiência. E cada tipo de enfiação passou a ser armazenada, ao invés de serem passados fio por fio a cada pedido de determinado artigo. O programa de treinamento visando aumentar a 


\section{PRODUÇÃO}

eficiência, e sua definição de método otimizado, foi concebido a partir da sugestão de um tecelão (ex-enfiador). Através destas melhorias foram introduzidos planos de incentivos para promover o maior envolvimento e dar mais motivação ao trabalhador, sendo pois o objetivo principal o de permitir que a atividade da enfiação tivesse a flexibilidade necessária para atender às flutuações de demanda e de tamanhos de lotes dos clientes, mantendo alto padrão de desempenho e se tornando uma vantagem competitiva nos negócios da empresa. O plano de incentivos teve como parâmetro a média diária de máquinas enfiadas/emendadas, acumuladas dia a dia, isto é, o total de enfiações programadas dividido pelo total de dias trabalhados no mês. O plano de incentivo foi escalonado em percentuais variáveis de $8 \%, 12 \%$ e $15 \%$.

A tinturaria, considerada a área mais complexa da fábrica, está recebendo maiores investimentos, como automação, criação de laboratório, contratação de técnicos e oferecimento de cursos de qualidade, por correspondência, para os trabalhadores - cursos que deverão se estender a todo o pessoal da fábrica. Segundo a chefia da seção, que foi contratada no decorrer dessas mudanças para levar a cabo essas transformações, é a área que mais se modificou em torno do conceito de qualidade. Bem porquê, nessa etapa - a de acabamento -, é a que pelo seu próprio processo produtivo tem acumulado no mercado mundial maiores avanços tecnológicos e que, por isso, existem maiores desenvolvimentos também na absorção das inovações tecnológicas. Nesta seção, está sendo implantado, simultaneamente, um sistema de premiação valorizando não só o aumento de produção mas, principalmente, a qualidade do artigo (redução de reprocesso), como forma de estímulo à mão-de-obra. Segundo a nova chefia do setor, este sistema de premiação busca enfrentar algumas características da mão-de-obra, "produtos de uma filosofia do setor e até mesmo da fábrica: um pessoal pouco qualificado, acomodado, desmotivado e sem perspectiva".

O empeçamento - responsável pela revisão, medição e empacotamento dos artigos -de todas as seções, foi a única que não chegou a sofrer modificações onde os equipamentos permaneceram obsoletos. É bom destacar que esta seção é praticamente a única que emprega mulheres (75), onde estão submetidas a um processo de trabalho monótono e repetitivo, com uma grande incidência de pequenos acidentes. As mudanças nos padrões de produção, com maior variabilidade dos artigos e maior exigência do mercado, ocasionaram uma aumento na demanda de trabalho desta seção, gerando uma intensificação do ritmo de trabalho. Segundo coordenador do programa, havia um projeto para a criação de um sistema de células para esta seção, que ia desde o empeçamento em si até o despacho, com a formação de duas linhas distintas, uma para artigos rígidos e outra para os elásticos. Tais mudanças nunca foram implementadas, primeiro em 


\section{PRODUÇÃO}

função da própria saída do coordenador do programa e, segundo porque tudo indica não ser, a área, prioritária para iniciativas deste teor.

Por fim, atualmente, está se realizando uma reestruturação do controle de qualidade, que busca trabalhar com uma delegação de normas e procedimentos de inspeção da qualidade aos operários, crescente importância da inspeção visual, com a utilização de auditorias internas.

Externamente, ao se procurar a melhoria da qualidade em todos os niveis do processo, também se está observando o padrão dos fornecedores de matériaprima, pois já se constatou muitos problemas provenientes de sua qualidade.

Outro esforço é a construção de uma memória técnica nas seções para haver o acúmulo das experiências, antes perdidas, favorecendo a introdução do Controle Estatístico de Processo (CEP), uma das grandes ferramentas utilizada pelo PQT. Para o CEP ser estabelecido, os operários retiram amostras de acordo com critérios preestabelecidos, medem características do produto, calculam estatísticas e imprimem os resultados em gráficos de controle.

Negando um dos princípios elementares PQT, a alta gerência da empresa não se envolveu com o processo de implantação do programa, deixando toda a sua responsabilidade a cargo da gerência de qualidade e produtividade.
Uma das tentativas para se ter a presença da direção, foi a realização de reuniões mensais com grupos de 20 a 30 pessoas, onde esta debatia com os trabalhadores. No entanto, explica o gerente de qualidade, "as pessoas tinham medo dele, baixavam a cabeça quando ele passava". Essa tentativa se frustrou muito em função do que esta fala expressa, a do caráter subordinado dos trabalhadores na relação paternalista estabelecida.

Assim, o não envolvimento por parte da direção e de algumas gerências, criou impasses que culminaram na demissão do próprio gerente de qualidade $e$ produtividade. Atualmente, o processo de continuidade do programa é apoiado por consultoria externa, que estipulou freqüentes reuniões com gerentes, propositadamente sem a presença do diretor, para discussão de problemas relativos a qualidade, fluxo de informações, implantação de uma linguagem mais técnica e maior velocidade nas decisões.

A despeito das contradições, o PQT teve alguns resultados. Para a empresa, nos seus dois primeiros anos, gerou um lucro de 550.000 dólares; eliminou a imensa variância do índice de qualidade como um todo e aumentou a rotação dos teares da tecelagem. Para os trabalhadores, de uma maneira geral, estes avaliam as mudanças como positivas, principalmente no que se refere às melhorias das condições de trabalho, como higiene, limpeza e organização nos locais de trabalho e aonde o novo equipamento representa menos risco de acidente. De uma maneira geral, verifica- 


\section{PRODUÇÃO}

se o aumento na transmissão da informação técnica através dos treinamentos. No entanto, identifica-se precárias condições de trabalho como exposição a poeiras, ruidos, temperaturas elevadas, iluminação deficiente e, especialmente, quanto ao ritmo acelerado de trabalho.

\section{Conclusão}

Pode-se perceber que o processo de modernização tecnológica,'não está sendo realizado de uma só vez, há uma grande heterogeneidade técnica. $\mathrm{Na}$ mesma indústria convivem antigos e novos equipamentos. $O$ impacto na empresa é pequeno, bastante limitado, sem alteração na sua estrutura.

As condições sócio-econômicas e políticas do país, segundo Carvalho \& Schmitz (1990), propiciam a adoção parcial das novas tecnologias. O seu uso seletivo produz ganhos na produtividade do trabalho, economias de matéria-prima e melhorias na qualidade. No caso da automação, esta acaba por concentrar-se em pontos estratégicos ou problemáticos da produção, quando há necessidade de precisão e qualidade. É o que mostra Abreu (1993:124), com base em estudo desenvolvido por Ferraz, onde "em 1990, $47 \%$ das empresas usavam processos automatizados em $10 \%$ das etapas do seu processo produtivo, mas apenas $11 \%$ das empresas tinham mais de $50 \%$ das etapas de produção automatizadas". E quanto às técnicas organizacionais, os dados são ainda mais indicativos: " $56 \%$ das empresas tinham algum programa de qualidade total, mas envolvendo apenas $20 \%$ de seus empregados".

Mesmo assim, os Programas de Qualidade Total colocam novas demandas para os trabalhadores, exigindo maior nível de abstração e responsabilidades, intensificando o ritmo de trabalho e provocando um desgaste físico e psíquico, modificando as relações mais imediatas do trabalhador com suas ações, seu corpo e sua subjetividade.

O estudo apontou ainda para a coexistência de situações de precárias condições de trabalho, ou de seu processo, com outras de sofisticadas exigências, que esbarra em uma força de trabalho com baixa escolaridade. Desenvolve-se um ambiente tenso sem ganhos concretos para os trabalhadores. Percebeu-se como esses programas são pensados para aumentar a qualidade do produto, sem contudo modificar a qualidade de vida dos trabalhadores. Além disso, essas práticas estão sendo incorporadas pelo empresariado brasileiro, de forma parcial e seletiva, com diferenças para as mulheres e homens.

Finalmente, o conceito de participação está mais relacionado com o envolvimento dos trabalhadores com os objetivos da empresa do que com a formação de trabalhadores com autonomia e poder de decisão. Portanto, ao se ter um projeto sem o envolvimento dos trabalhadores e dos sindicatos, se favorece a permanência do descompasso entre desenvolvimento técnico e social. 
Recomenda-se como fundamental para a implantação de tais programas um levantamento preliminar do perfil dos trabalhadores e essencialmente das relações sócio-culturais da empresa, para a obtenção de resultados mais consistentes e duradouros, estabelecendo-se entre a empresa e os trabalhadores uma real cooperação.

Recebido em: $26 / 06 / 97$ Recebido após revisão: 16/02/98 Aceito em: 04/05/98 Publicado em: 27/07/98

\section{Bibliografia}

ABREU, A., 1993. Mudança tecnológica e gênero no Brasil: primeiras reflexões. Novos Estudos CEBRAP, 35: 121-132.

CARVALHO, R. Q. \& SCHMITZ, H., 1990. O fordismo está vivo no Brasil. Novos Estudos CEBRAP, 27: 148-156.

CORIAT, B., 1994. Pensar pelo Avesso: $O$ Modelo Japonês de Trabalho e Organização. Rio de Janeiro: UFRJ/ Revan.

FERREIRA, C. G. et al., 1991. Alternativas sueca, italiana e japonesa, ao paradigma fordista: elementos para uma discussão sobre o caso brasileiro. Seminário Interdisciplinar "Modelos de Organização Industrial, Política Industrial e Trabalho". ABET Associação Brasileira de Estudos do Trabalho.
HARVEY, D., 1994. Condição pósmoderna. São Paulo: Edições Loyola.

HUMPHREY, J., 1989. Novas formas de organização do trabalho na indústria: suas implicações para o uso e controle da mão-de-obra no Brasil. In: Seminário Padrões Tecnológicos e Políticas de gestão: comparações internacionais. Anais, São Paulo: USP/UNICAMP.

LEITE, M., 1993. Novas formas de gestão da mão-de-obra e sistemas participativos, Uma tendências à democratização das relações de trabalho? Educação \& Sociedade, 14(45): 190210 .

TAUILE, J. R., 1993. Estado e desenvolvimento capitalista: propostas para um projeto contemporâneo. Boletim de Conjuntura. Rio de Janeiro, 12(3): 93116.

WEISS, J.; RABECHINI, R Jr.\& HWA, C., 1993. Indústria têxtil: oportunidades para instituições de pesquisa. Revista de Administração, 28(1): 65-74. 